\title{
Study of Mechanical and Physical Properties of Palm Fiber Reinforced Acrylonitrile Butadiene Styrene Composite
}

\author{
Budrun Neher ${ }^{1,2 *}$, Md. Mahbubur Rahman Bhuiyan², Humayun Kabiri', Md. Rakibul Qadir ${ }^{3}$, \\ Md. Abdul Gafur ${ }^{3}$, Farid Ahmed ${ }^{1}$ \\ ${ }^{1}$ Department of Physics, Jahangirnagar University, Dhaka, Bangladesh; ${ }^{2}$ Department of Physics, Comilla University, Comilla, Bang- \\ ladesh; ${ }^{3} \mathrm{PP}$ and PDC, Bangladesh Council of Scientific and Industrial Research, Dhaka, Bangladesh. \\ Email: "budrunneher@gmail.com
}

Received November 29 ${ }^{\text {th }}, 2013$; revised December 21 $1^{\text {st }}, 2013$; accepted January $6^{\text {th }}, 2014$

Copyright (C) 2014 Budrun Neher et al. This is an open access article distributed under the Creative Commons Attribution License, which permits unrestricted use, distribution, and reproduction in any medium, provided the original work is properly cited. In accordance of the Creative Commons Attribution License all Copyrights (C) 2014 are reserved for SCIRP and the owner of the intellectual property Budrun Neher et al. All Copyright (C) 2014 are guarded by law and by SCIRP as a guardian.

\section{ABSTRACT}

Palm fiber (PF) reinforced acrylonitrile butadiene styrene (ABS) composite matrix was prepared by employing Injection Moulding Machine (IMM). Palm fiber was collected from ten different trees of different age group from Comilla region in Bangladesh. Three sets of samples were prepared for three different wt $\%(5 \%, 10 \%$ and $\mathbf{2 0 \%}$ ) of fiber contents. The mechanical (tensile strength, flexural stress, micro hardness, Leeb's rebound hardness) and physical (bulk density and water absorption) properties were measured. The observed result reveals that the tensile strength (TS) and flexural stress (FS) were decreased with increasing fiber contents in the PF-ABS composites except $10 \%$ fiber content.

\section{KEYWORDS}

\section{Acrylonitrile Butadiene Styrene; Composite; Tensile Stress; Flexural Stress; Vicker’s Hardness and Leeb’s} Rebound Hardness

\section{Introduction}

Although composite materials had been known in various forms throughout the history of mankind, the history of modern composites probably began in 1937 when salesmen from the Owens Corning Fiberglass Company began to sell fiberglass to interested parties around the United States [1]. Over the last thirty years, composite materials, plastics and ceramics have been the dominant emerging materials. The volume and number of applications of composite materials have grown steadily, penetrating and conquering new markets relentlessly. Modern composite materials constitute a significant proportion of the engineered materials market ranging from everyday products to sophisticated niche applications. While composites have already proven their worth as weight-saving materials, the current challenge is to make them cost effective. The efforts to produce economically attractive composite com-

*Corresponding author. ponents have resulted in several innovative manufacturing techniques currently being used in the composites industry.

Composite is defined as solid materials, which consists of a combination of two or more materials in which the individual component retains their separate identity [2]. Composite materials are widely used in many fields such as: civil, industrial, military, space craft, and biomedical application, mainly because of their excellent thermo mechanical properties [3]. Traditional plastic materials are reinforced by glass fibers, which are both expensive and harmful to the environment [4].

One of the major environmental problems we are facing today is the plastic waste problem. The tremendous production and use of plastics in every segment of our life have increased the plastic waste in huge scale. The waste disposal problems have directed great part of the scientific research to eco-composite materials that can be easily degradable and bio assimilated $[5,6]$. The use of natural fiber as reinforcement for composites has received 
increasing attention and polymer based composites having natural fiber as reinforcement have the potential to be attractive alternative to synthetic fiber composites.

Natural fiber reinforcement increases biodegradability, reduces cost and decreases environmental pollution and hazards. Recently many types of natural fibers have been investigated for use in plastics including palm, flax, hemp, jute, straw, wood, rice husk, wheat, barley, oats, rye, bamboo, sugarcane, grass reeds, kenaf, ramie, sisal, coir, banana fiber etc. [4]. Among these fibers, palm fiber is one of the particular interests because palm fiber (Palmyra Palm) grows plenty in Bangladesh and all over the world and composites made of palm fibers have moderate tensile and flexural properties compared with other natural fibers.

Acrylonitrile butadiene styrene (ABS) is a common thermoplastic terpolymer made by polymerizing styrene and acrylonitrile in the presence of poly butadiene. The proportions of contents in ABS can vary from $15 \%$ to $35 \%$ acrylonitrile, $5 \%$ to $30 \%$ butadiene and $40 \%$ to $60 \%$ styrene. The nitrile groups from neighboring chains, being polar, attract each other and bind the chains together, making ABS stronger than pure polystyrene. The styrene gives the plastic a shiny, impervious surface. The butadiene, a rubbery substance, provides resilience even at low temperatures. For the majority of applications, ABS can be used between -20 and $80^{\circ} \mathrm{C}$ as its mechanical properties vary with temperature [7]. The properties are created by rubber toughening, where fine particles of elastomeric are distributed throughout the rigid matrix.

A large number of experiments have performed with natural fiber reinforced polymeric composites all over the world. Mohammad, N. N. B. et al. [8] carried out research on the mechanical properties of kenaf fiber reinforced rPET/ABS composites. They observed that there was a slightly decrement in mechanical properties with addition of kenaf fiber. Rafia Akter et al. [4] observed that the tensile strength decreased with the increase of talc content in the composites.

Palm fiber would be a good reinforcing agent in ABS and will be a good area of research. With the addition of palm fiber in ABS, polymeric matrix could change the mechanical and physical properties of the composites. Therefore, the mechanical (tensile strength, flexural stress, micro hardness, Leeb's rebound hardness) and physical (bulk density \& water absorption) properties were measured in the palm fiber reinforced ABS composites in this study.

\section{Materials and Methods}

\subsection{Sample Collection and Preparation of Composite}

Palm leaves of ten different aged trees (five of them are above 10 years and another five of them are below 10 years) were collected from Burura region of Comilla district. Dividing ends of the middle hard part of the leaves were hammered. Hard part of the leaves was immersed in water for 20 days to rotten. Rotten materials were cleaned and fiber were then separated and dried under sun light. After that fiber was kept at $100^{\circ} \mathrm{C}$ for 24 hours for partial removal of moisture. Acrylonitrile butadiene styrene (ABS) was collected from local market of old Dhaka of Bangladesh. After measuring some properties (Physical: Water absorption, Mechanical: Tensile strength and Thermal: TG/DTG) of palm fiber and ABS polymer, Palm fiber was cut to $1-2 \mathrm{~mm}$ in sized. ABS and small palm fiber were dried in dryer at $50^{\circ} \mathrm{C}$ for 24 hours. Fined palm fiber and ABS polymer put into the injection moulding machine. This mixture was heated at $150^{\circ} \mathrm{C}$ inside the injection moulding machine and molten mixture become composite and come out of the IMM. This composite was poured into different shape of die for different test. Three sets of composites samples (with 5\%, $10 \%$ and $20 \%$ fiber content) were prepare to carry out this research.

\subsection{Characterization of PF-ABS Composite}

\subsubsection{Mechanical Properties of PF-ABS Composite}

1) Tensile and Flexural Property of Composite

Mechanical property such as TS and percentage of elongation-at break $[\mathrm{EB}(\%)]$ of the samples were measured by a universal testing machine (Hounsfield UTM 10 KN; ASTM D 3039/D 3039 M-00) [9] at a crosshead speed of $2 \mathrm{~mm} / \mathrm{min}$, keeping a gauge length of $50 \mathrm{~mm}$. FS and flexural strain (\%) were also measured by the same apparatus [10], keeping a distance of $70 \mathrm{~mm}$ between two supports on which the samples were placed to employ load. The test samples were conditioned at $50^{\circ} \mathrm{C}$ for 24 hours before testing. All the tests were performed under the same condition.

2) Hardness of Composite

A software controlled Vicker's square based diamond indenter (Shimadzu, Japan) was employed to measure the micro hardness $(\mathrm{H})$ from the residual impression on the sample surface after an indentation time of 6 seconds. Loads of $245.2 \mathrm{mN}, 490.3 \mathrm{mN}$ and $980.7 \mathrm{mN}$ were used to derive a load indentation value of $\mathrm{H}$ in MPa by the following relation [11].

$$
H=K \frac{P}{d^{2}}
$$

where $d(m)$ is the length of indentation diagonal, $P(N)$ is the applied load and $K$ is a geometrical factor equal to 1.891. Sample with flat and smooth surface immediately after their preparation were used for this measurement. At least five imprints were taken on the sample surface for each load, and the $H$ was calculated from the average 
value of all impressions.

Leeb's rebound hardness test is one of the most used methods for testing hardness. The portability of Leeb's tester can sometimes help to achieve higher testing rates without destruction of samples, which in most of the cases thus simplifies process and saves costs [12]. It uses a carbide ball hammer that is spring rather than gravity powered. An electronic sensor measures the velocity of the hammer as it travels toward and away from the surface of the sample. The Leeb's value is the hammer's rebound velocity divided by the impact velocity times 1000. The result is Leeb's hardness from 0 to 1000 that can be related to other hardness scales such a Vickers.

\subsubsection{Physical Properties of PF-ABS Composites}

1) Bulk Density of Composites

The bulk density of the composite materials was determined by measuring the weight and dimensions of the composite samples by using the following relation.

$$
D=\frac{W_{t}}{L \times W \times H}
$$

where $W_{t}, L, W$ and $H$ are the weight, length, width and height of the composites respectively. The samples were dried into dryer at $50^{\circ} \mathrm{C}$ for 24 hours before measuring the density. Average densities were obtained using result from ten samples of each group.

2) Water Absorption Property of Composite

The water absorption ability of the palm fiber reinforced ABS composites was carried out according to ASTM D 570-98 [13]. It was measured by soaking the samples in three glass beaker (for $5 \%, 10 \%$ and $20 \%$ ) of water at $25^{\circ} \mathrm{C}$ for different periods (upto 576 hours). The weight of the samples was measured before immersion of the sample. After certain period of times as $1,2,24,48$, 72, 168, 192, 216, 240, 380, 480, 504 and 576 hours, samples were taken out from the water, wiped using tissue papers and then measured weight. The water uptake (mass gained) was measured by subtraction of initial weight from final weight. The percentage of water absorption was determined by using the formula [14].

$$
W_{g}=\frac{W_{a}-W_{o}}{W_{o}} \times 100
$$

Where $W_{a}$ and $W_{o}$ are the weight of the sample after and before soaking in water.

\section{Results and Discussion}

\subsection{Mechanical Properties of PF-ABS Composites}

3.1.1. Tensile and Flexural Property of Composites The result of the mechanical tests in terms of tensile strength, flexural strength is presented in Figures 1-6.
Figure 1 shows the tensile strength of the ABS composites decreased with the increase of fiber content upto 5\%. After 5\% fiber content in ABS composite, TS increased slightly upto $10 \%$. After $10 \%$ upto $20 \%$ tensile strength decreased again. The percentage of change of the tensile strength with respect to $0 \%$ fiber are $13.8 \%$ (for $5 \%$ ), $9.4 \%$ (for $10 \%$ ) and $13.3 \%$ (for $20 \%$ ). The tensile strength depends on number of factors-fiber loading, matrix strength, fiber adhesion between fiber and matrix, orientation of fiber etc. For short fiber, the interfacial bonding is important. For this composites the adhesion between ABS - fiber is poor. The fiber loading is less than critical volume in $5 \%$ fiber in composites. As a result the tensile strength decreased with the increase of fiber.

Seung-Hwan et al. [15] showed that the tensile strength gradually decreased with the increase of fiber content. This may be due to poor interfacial adhesion between polymer matrix and fiber. This is general phenomenon in incompatible composites with different characteristics, such as hydrophobicity of the polymer matrix and hydrophilicity of the filler.

The effect of palm fiber loading on elongation at break of PF-ABS composites is shown in Figure 2. In this graph it is shown that without fiber the elongation break (\%)/strain (\%) is maximum. The elongation at break rapidly decreased after palm fiber was introduced in the ABS polymer but it is slightly increased when $10 \%$ of palm fiber is added into the ABS polymer. After that elongation at break again decrease at $20 \%$ palm fiber. Elongation at break showed a significant decrease with increasing fiber loading which indicates hindrance by fiber to molecular mobility or deformability of polyester matrix. It is also derive that elongation at break decreased with increasing fiber content in all composites. This may be due to the increase in the discontinuity of the polymer matrix with the increase in the dispersed phase $[15,16]$.

Figure 3 shows flexural strength of polymer matrix composites with different wt (\%) of palm fiber. From figure it is shown that flexural strength decreased drastic-

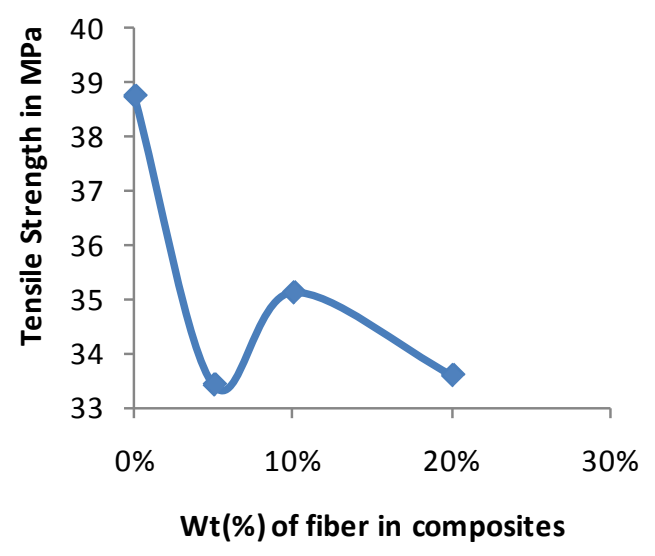

Figure 1. TS vs wt (\%) of fiber in composites. 


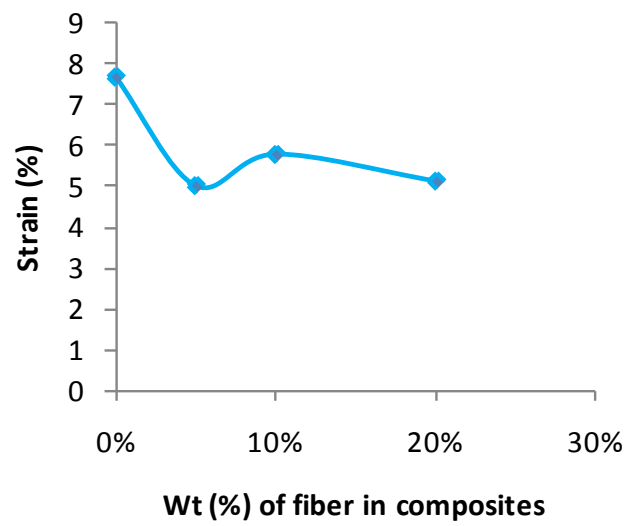

Figure 2. Strain (\%) vs wt (\%) of fiber in composites.

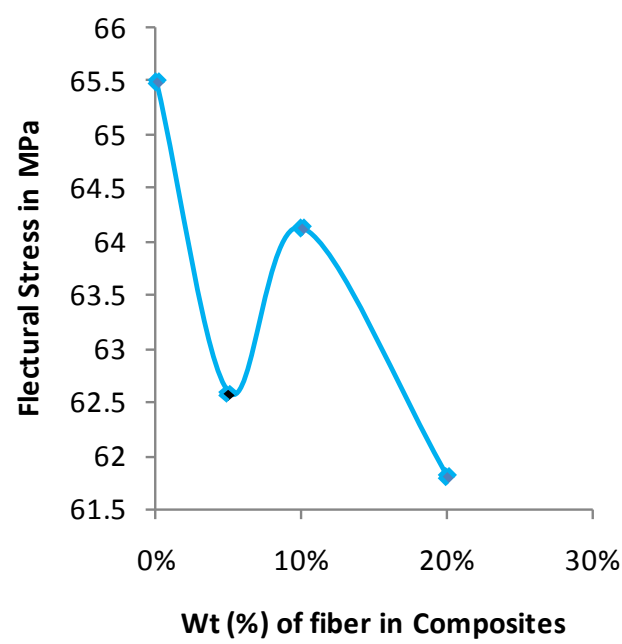

Figure 3. FS vs wt (\%) of fiber in composites.

cally with $5 \%$ fiber content. Then it increased for $10 \%$ fiber and again decreased for $20 \%$ fiber reinforced composites. For virgin ABS sample the flexural strength is $65.5 \mathrm{MPa}$, for $5 \%, 10 \%$ and $20 \%$ fiber content in composites is 62.5 MPa, 64.2 $\mathrm{MPa}$ and $61.57 \mathrm{MPa}$ respectively and indicates that the filler-matrix interaction is in poor performance.

Figures 4-6 show the tensile stress-strain curve of the randomly selected composites with 5\%, 10\% \& 20\% fiber. The tensile stress for composites with $5 \%, 10 \%$ and $20 \%$ fiber contents are 37.32 MPa (C1S1), 39.3 MPa (C2S2) and 38.32 MPa (C3S7) respectively. By comparing three figures it is seen that tensile stress is slightly higher for $10 \%$ fiber contents in the composites.

Natural fiber and their composites are environmental friendly and renewable, however they have several bottlenecks. They have poor wet ability, incompatibility with some polymeric matrices and high moisture absorption. Due to high moisture absorption properties, there are formations of void in the composites which can reduce the mechanical properties of composite such as flexural strength $[8,17]$.

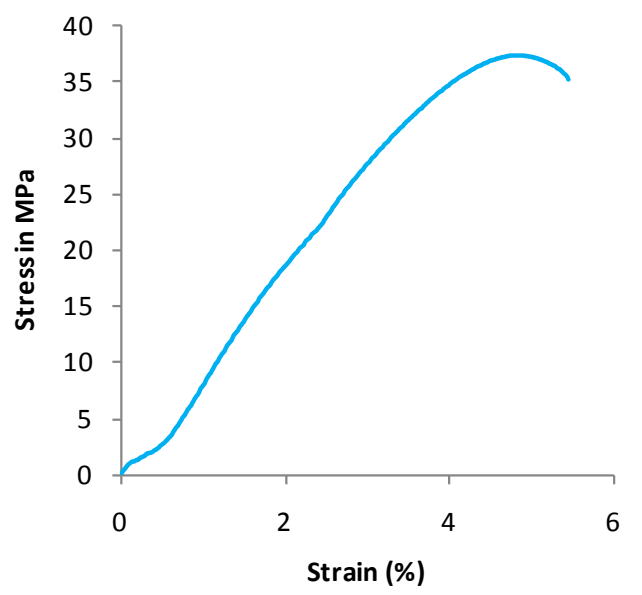

Figure 4. Stress vs strain (\%) curve of sample (C1S1).

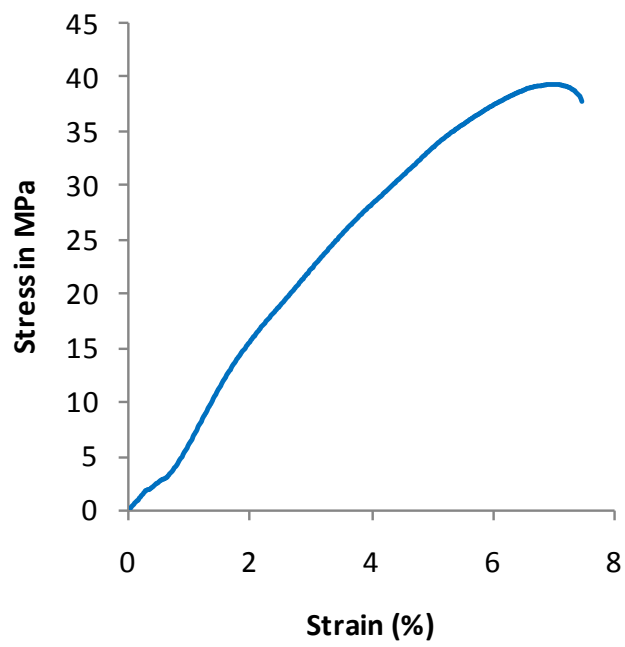

Figure 5. Stress vs strain (\%) curve of sample (C2S2).

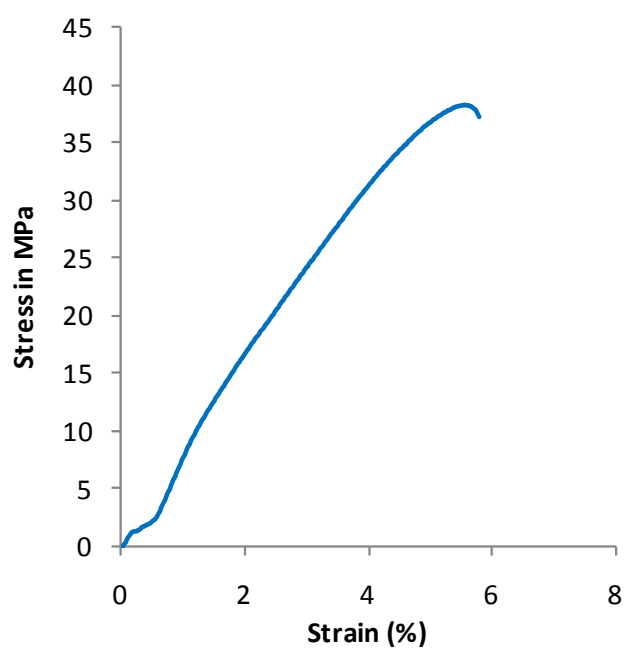

Figure 6. Stress vs strain (\%) curve of sample (C3S7).

\subsubsection{Hardness of the Composite}

Figure 7 shows the effect of addition of palm fiber in PF-ABS composites. It reveals that with the increase of 
palm fiber content in the composites, the Vicker's micro hardness decreased.

Figure 8 shows a graph of micro hardness with a different load scale. It is seen that composites shows more or less same hardness for different loads. Before performing each of the experiment, all the samples were dried at $50^{\circ} \mathrm{C}$ in dryer. After that it may contain some moisture content. C. Tan et al. [18] showed that due to high moisture absorption properties, there are formations of void in the composites which can reduce the mechanical properties of composite such as hardness. Bhuiyan, A. H. et al. [19] showed that with the inclusion of $\mathrm{TiO}_{2}$, the hardness of the composites decreased. This conclude that the composite materials were somewhat soften by the addition of filler. Figure 9 shows the Leeb's rebound hardness for different wt (\%) of fiber

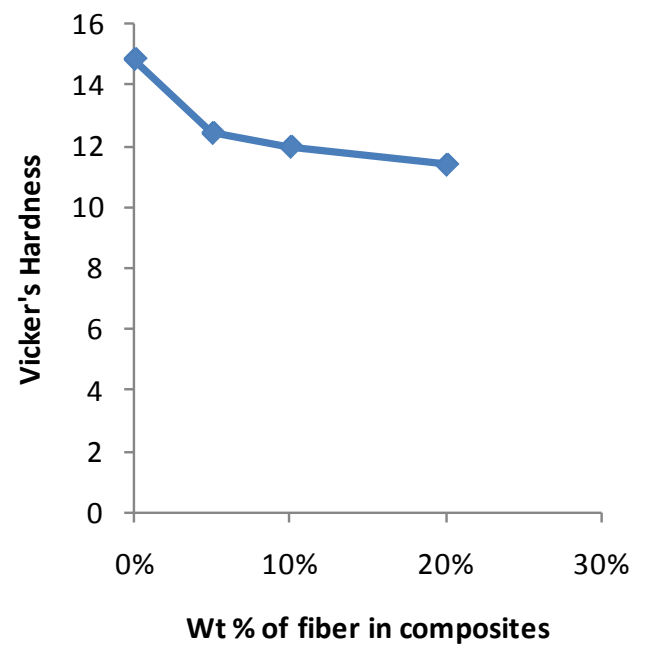

Figure 7. Average Vicker's hardness vs wt (\%) of fiber in ABS composites. content composites. Leeb's rebound hardness increased with increase of fiber content in composites. Since the micro hardness decreased, which will create more rebound velocity, and then finally Leeb’s hardness increased.

\subsection{Physical Properties of PF-ABS Composites}

\subsubsection{Bulk Density of Composites}

Figure 10 shows the effect of fiber loading in the PFABS composites. Figure 10 indicates that the bulk density of the composites is not homogeneous under the same condition. Bulk density is small in value for composites with 5\% fiber. After 5\% fiber in composite, bulk density is increased with the increase the fiber content in the composites. The samples used for bulk density did not follow the same size in injection moulding machine because pressure was given manually. When the pressure was low, the molten composites did not pour the same die homogeneously, which might vary the size and weight of the samples.

\subsubsection{Water Absorption Property of Composites}

The effect of the addition of fiber content on the water absorption behavior of the composites is shown in Figure 11. The water absorption of the composites was found to increase with increased palm fiber content as shown in Figure 11. The first 72 hours of immersion showed a rapid increase in the level of water absorption of the PF-ABS composites. The next 504 hours showed gradual increase in the water uptake, and the samples finally reached a plateau for the rest of the testing period. Additionally, the water absorption increased with soaking time, but the rate of absorption decreased over time for all of the PF-ABS composites.

Generally polymer likes ABS and polylactic acid can

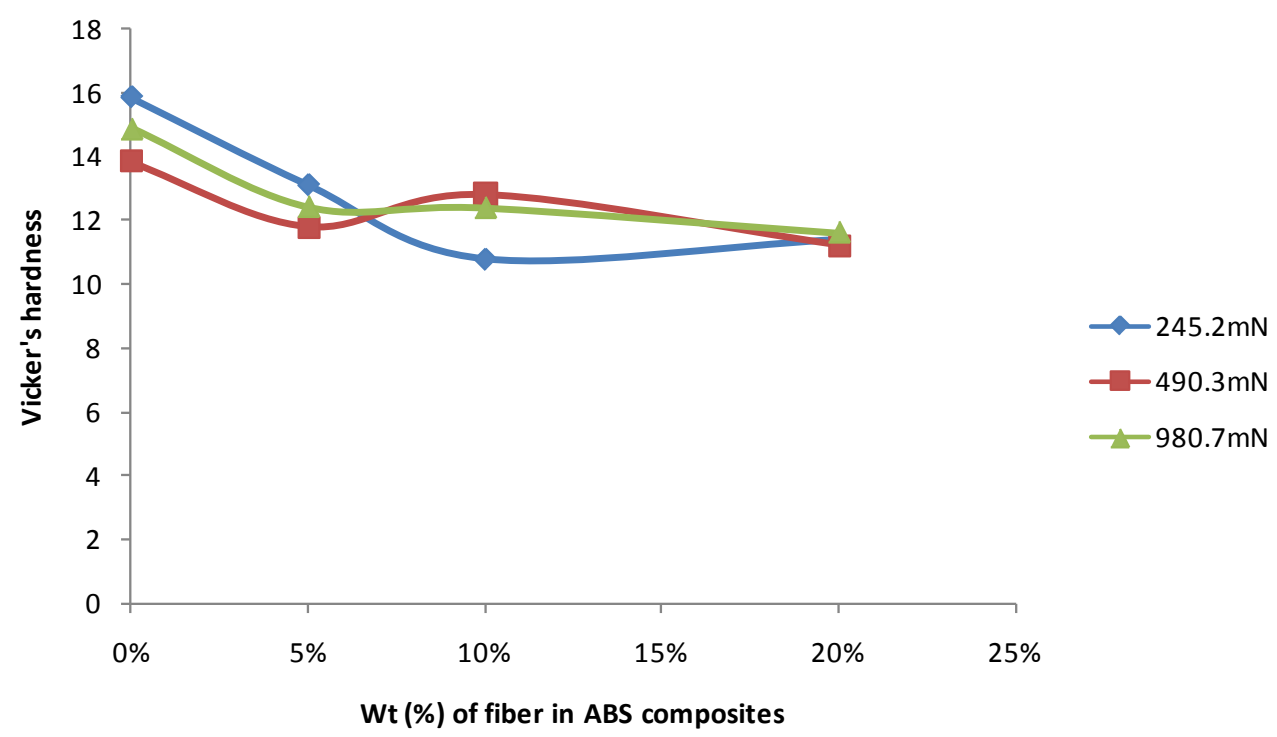

Figure 8. Vicker's hardness vs wt (\%) of fiber in ABS composites for different loads. 


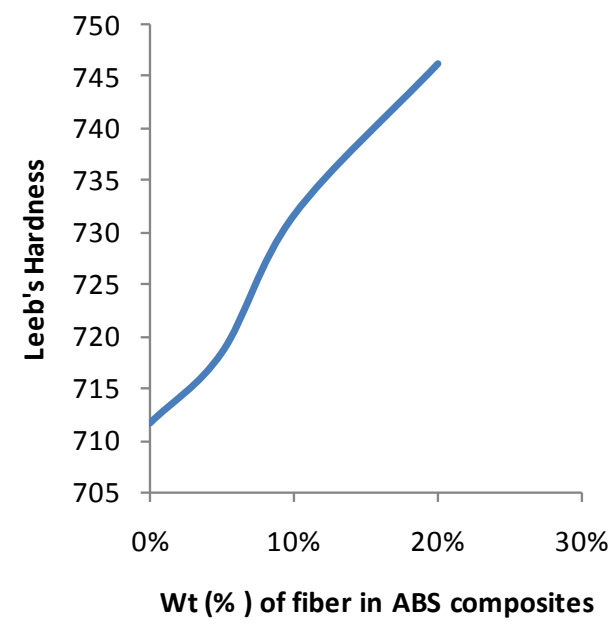

Figure 9. Leeb's Rebound Hardness vs wt (\%) of fiber in composites.

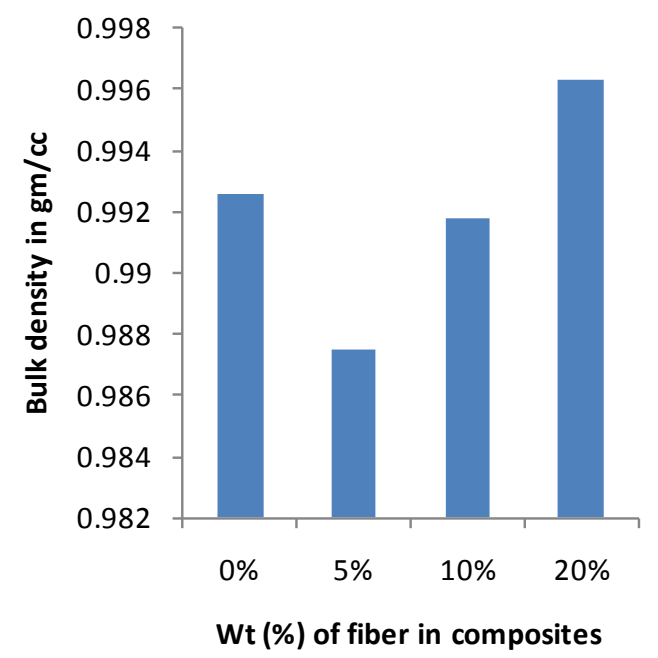

Figure 10. Bulk density vs wt (\%) of fiber in composites.

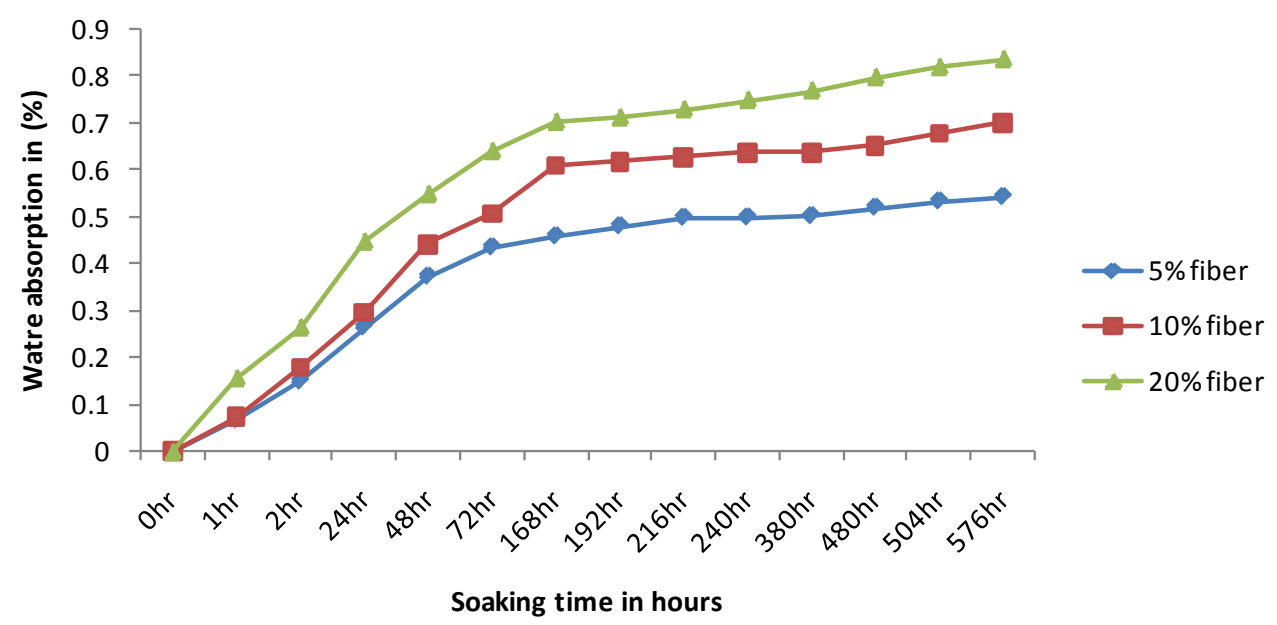

Figure 11. Water absorption (\%) vs soaking time in hours.

absorb small amount of water while the PF-ABS composites absorbs more water due to the hydrophilic nature of the palm fiber (due to presence of polar group).Water may penetrate into the composite through the cutting/ interfacial side of the sample [20] that allowed hydrogen bonding to occur between the free hydroxyl group of the cellulosic molecules with water molecule. During the first 72 hours, the water caused the fiber cell wall to swell and caused the fiber to expand until the cell wall becomes saturated with water. At later time composites reached a constant water uptake beyond which water exists as free water in the void structure and does not contribute to further expansion [21]. At higher palm fiber content, however, there were more free hydroxyl group to interact and absorb water compound to composites with lower palm fiber contents.

\section{Conclusion}

The mechanical and physical behavior of palm fiber rein- forced ABS composites was studied. The mechanical properties did not change in the same ratio. The mechanical properties like tensile and flexural properties are the highest at $10 \%$ palm fiber content in the PF-ABS composites. This was attributed to the fact that the random fiber orientation resulted in lower properties. Treatment of palm fiber in ABS matrix does not bring regular and considerable change in the mechanical properties of the composites. Physical properties as water absorption property showed that with the increase of fiber content in the composites, water absorption increases.

\section{REFERENCES}

[1] A. Brent Strong, "History of Composite Materials-Opportunities and Necessities," Brigham Young University, 2006.

http://strong.groups.et.byu.net/pages/articles/articles/histo ry.pdf

[2] T. Richardson, “Composite: A Design Guide,” Industrial 
Press, 1987.

[3] R. A. Khan, M. A. Khan, H. U. Zaman, N. Noor, T. Huq, A. Khan, K. Dey, B. Sarker, S. Saha, M. M. Rahman, M. Saha and M. A. Gafur, "Study on the Mechanical and Thermal Properties of Jute-Reinforced Methyl Acrylate Grafted PET Composites,” Polymer-Plastic Technology and Engineering, Vol. 49, 2010, pp. 373-380.

[4] R. Akter, R. Sultana, Md. Z. Alam, Md. R. Qadir, M. H. A. Begum and Md. A. Gafur, "Fabrication and Characterization of Woven Natural Fiber Reinforced Unsaturated Polyster Resin Composites,” International Journal of Engineering \& Technology, Vol. 13 No. 2, 2013, pp. 122-128.

[5] S. Selke, "Biodegradation and Packageing,” Pira International Reviews: Surrey, UK, 1996.

[6] M. Avella, E. Bonadies, E. Martusecelli and R. Rimedio, "European Current Standardization for Plastic Packaging Recoverable through Composting and Biodegradation," Polymer Testing, Vol. 20, No. 5, 2001, pp. 517-521. http://dx.doi.org/10.1016/S0142-9418(00)00068-4

[7] “Acrylonitrile Butadiene Styrene (ABS),” 2010. http://en.wikipedia.org/wiki/Acrylonitrile_butadiene_styr ene

[8] N. N. B. Mohammad and A. Arsad, "Mechanical, Thermal and Morphological Study of Kenaf Fiber Reinforced rPET/ABS Composites,” Malaysian Polymer Journal, Vol. 8, No. 1, 2013, pp. 8-13.

http://www.paspk.org/proceedings/44\%20No.\%202/7ce0 b7abproc44-2-7.pdf

[9] ASTM Designation: D 3039/D 3039M-00, "Standard Test Method for Tensile Properties of Polymer Matrix Composites Materials".

[10] ASTM Designation: D 790-00, “Standard Test Method for Flexural Properties of Unreinforced and Reinforced Plastics and Electrical Insulating Materials”.

[11] F. J. Balta Calleja and S. Fakirov, "Microhardness of Polymer,” Cambridge University Press, UK, 2000.

[12] P. P. Budnikov, "The Technology of Ceramic and Refractories,” M. I. T Press, Cambridge, 1964.

[13] ASTM Designation: D 570-98, "Standard Test Methods for Water Absorption of Plastics”.

[14] M. Naznin, Md. Z. Abedin, M. A. Khan and Md. A. Gafur, "Influence of Acacia catechu Extracts and Urea and Gamma Irradiation on the Mechanical Properties of Starch/PVA-Based Material," International Scholarly Research Network (ISRN), Polymer Science, Vol. 2012, 2012, Article ID: 348685. http://dx.doi.org/10.5402/2012/348685

[15] S.-H. Lee and S. Q. Wang, "Biodegradable Polymers/ Bamboo Fiber Biocomposite with Bio-Based Coupling Agent,” Composites: Part A, Vol. 37, 2006, pp. 80-91.

[16] I. Ahmad, D. R. Abu Bakar and S. N. Mokhilas, "Recyled PET for Rice Husk/Polyester Composites,” AJSTD, Vol. 22, No. 4 pp. 345-353. http://eprints.utp.edu.my/3294/

[17] S. Taj, M. A. Murawar and S. Khan, "Natural Fiber-Reinforced Polymer Composites," Proceedings of the Pakistan Academy of Sciences, Vol. 44, No. 25, 2007, pp. 129-144.

[18] C. Tan, I. Ahmad and M. Heng, "Characterization of Polyester Composites from Recycled Polyethylene Terephthalate Reinforced with Empty Fruit Bunch Fibers," Materials and Design, Vol. 32, No. 8-9, 2011, pp. 44934501.

http://www.sciencedirect.com/science/article/pii/S026130 6911002007

[19] A. H. Bhuiyan, M. F. Mina, S. Seema, M. M. Khan, M. J. Rahman and M. A. Gafur, "Structural, Elastic and Thermal Properties of Titanium Dioxide Filled Isostatic Polypropylene,” Journal of Polymer Research, Vol. 18, No. 5, 2011, pp. 1073-1079. http://dx.doi.org/10.1007/s10965-010-9509-y

[20] J. A. Khan, M. A. Khan, R. Islam and A. Gafur, "Mechanical, Thermal and Interfacial Properties of Jute Fabric-Reinforced Polypropylene Composites: Effect of Potassium Dichromate," Material Science and Application, Vol. 1, No. 6, 2010, pp. 350-357. http://dx.doi.org/10.4236/msa.2010.16051

[21] R. M. Rowell and H. P. Stout, "Jute and Kenaf in Handbook of Fiber Chemistry,” Marcel Dekkar, Inc., New York, 1998. 